\title{
Lymphoscintigraphy for Sentinel Lymph Node Biopsy in Breast Cancer: Do We Need a Delayed Image?
}

\author{
Nadja Taumberger ${ }^{\mathrm{a}} \quad$ Birgit Pernthaler $^{\mathrm{b}}$ Thomas Schwarz ${ }^{\mathrm{b}}$ \\ Vesna Bjelic-Radisic ${ }^{a} \quad$ Gunda Pristauz $^{\mathrm{a}}$ Reingard M. Aigner ${ }^{\mathrm{b}}$ Karl Tamussino ${ }^{\mathrm{a}}$ \\ a Division of Gynecology, Department of Obstetrics and Gynecology, Medical University of Graz, Graz, Austria; \\ ${ }^{\mathrm{b}}$ Division of Nuclear Medicine, Department of Radiology, Medical University of Graz, Graz, Austria
}

\section{Keywords}

Breast cancer - Sentinel node biopsy - Delayed image

\begin{abstract}
Background: Sentinel lymph node biopsy has become a standard of care in the treatment of patients with early breast cancer, but clinical guidelines continue to be vague on details of the procedure. We were interested in the results of our 2-day protocol, which includes delayed lymphoscintigraphy at $18 \mathrm{~h}$. Methods: We reviewed the results of preoperative lymphoscintigrams in patients undergoing surgery for breast cancer. Lymphoscintigraphy was performed $2 \mathrm{~h}$ after periareolar injection of $4 \times 37 \mathrm{MBq}{ }^{99 \mathrm{mTc} \text { nanocolloid }}$ (early lymphoscintigraphy) and $18 \mathrm{~h}$ following injection (delayed lymphoscintigraphy). The early results were compared with the late results. Results: A total of 238 lymphoscintigraphies were performed in 232 patients ( 6 bilateral). At $2 \mathrm{~h}, \geq 1$ sentinel nodes were visualized in 154/238 (65\%) cases; in 84 (35\%), no sentinel node was visualized. Delayed lymphoscintigraphy visualized a sentinel node in 40 of 76 (53\%) cases with no visualization at $2 \mathrm{~h}$ and failed to show a sentinel node in $36(47 \%)$ of these cases (in 8 cases, no delayed lymphoscintigram was obtained). Conclusions: Delayed lymphoscintigraphy was useful in about $50 \%$ of the breast cancer patients in whom immediate scintigraphy failed to demonstrate a sentinel lymph node.

(c) 2019 S. Karger AG, Basel
\end{abstract}


Table 1. Patient demographics $(n=232)$ and tumor characteristics of the overall study cohort

\begin{tabular}{lc}
\hline Mean age, years (range) & $60.1(24-89)$ \\
Tumor, $n(\%)$ & $124(52)$ \\
Right side & $114(48)$ \\
Left side & $(n=197)$ \\
pT stage, $n(\%)$ & $1(0.5)$ \\
pT0 & $20(10)$ \\
pTis, DCIS & $2(1)$ \\
pT1 & $16(8.1)$ \\
pT1a & $54(27)$ \\
pT1b & $76(39)$ \\
pT1c & $26(13)$ \\
pT2 & $1(0.5)$ \\
pT2c & $1(0.5)$ \\
pT3 & $(n=41)$ \\
yT stage, $n(\%)$ & $13(32)$ \\
yT0 & $6(15)$ \\
yTis, DCIS & $1(2.4)$ \\
yT1 & $5(12)$ \\
yT1a & $4(10)$ \\
yT1b & $8(20)$ \\
yT1c & $4(10)$ \\
yT2 &
\end{tabular}

cording to the protocol, the tracer $\left(4 \times 37 \mathrm{MBq}{ }^{99 \mathrm{~m}} \mathrm{Tc}\right.$ nanocolloid $)$ is injected subcutaneously periareolarly on the afternoon before surgery. Planar static images in the anterior and lateral perspectives are then obtained $2 \mathrm{~h}$ following the injection (p.i.). On the following day in the morning, at about $18 \mathrm{~h}$ p.i., delayed images are obtained. SPECT-CT has been done since 2011 in most cases.

Patients are operated on the morning after tracer injection. Intraoperatively SLNs are identified with a gamma probe. In cases where scintigraphy failed to identify an SLN, blue dye is injected additionally.

We reviewed patient records for stage of the disease, previous breast surgery, previous (neoadjuvant) chemotherapy, neoadjuvant antihormonal therapy, and breast biopsy within 7 days of scintigraphy. We reviewed the scans to identify how many nodes were seen early and how many were seen late to address the issue whether the late scan provided additional information.

The study protocol was approved by the institutional Ethics Committee; written informed consent was waived because of the retrospective study design.

\section{Results}

We analyzed 238 scans in 232 patients (6 women had bilateral SNB). Patient data and clinical and pathological data are summarized in Table 1.

\section{SLN Detection Rate at Scintigraphy}

Five early scintigrams (2\%) were no longer available for review. SLNs were seen in the early readings in 149 of 238 scintigrams, for an early detection rate of $63 \%$. Of interest are the 84 scintigrams in which the early reading showed no sentinel node (SN). 76 of these patients had late scintigrams, 40 (53\%) of which showed a node. Thus, the overall scinitgraphic detection rate was $81 \%$ (Fig. 1).

In $124 / 204$ cases (61\%), early and late lymphoscintigraphy showed the same number of SNs. In 67/204 cases (33\%), delayed images showed more lymph nodes than the early images (Fig. 2). In 13/204 cases (6\%), the early images showed more SNs than the delayed images.

\section{SLN Detection Rate at Surgery}

SLNs were found at surgery in all 193 patients with positive early or late scintigraphy. This leaves 45 negative scintigraphies ( 36 cases with no visualization at early and late scintigraphy, 8 cases with no visualization in early scintigraphy and no late scintigraphy, and 1 case with late scintigraphy only). In 33 of these 45 cases (73\%), blue dye was injected before the incision to visualize the SLN. This procedure led to the detection of SNs in 31 (69\%) of the 45 axillae with negative scintigraphy. In 12 cases, preoperative lymphoscintigraphy showed no SNs and blue dye was not injected. 6 of these cases had nodes detected with intraoperative scintigraphy and 6 underwent axillary dissection. Altogether, with the combination of lymphoscintigraphy and facultative blue dye, the overall detection rate for SNs at the time of surgery was $94 \%$ (224 of 238 axillae).

\section{Patients after Neoadjuvant Chemotherapy}

Twenty-seven patients had received neoadjuvant chemotherapy before surgery. 24 (89\%) of these patients had both early and delayed scans. 18 of the 24 early scans (75\%) showed an SN; the delayed image showed an SN in 1 of the 6 remaining cases (16\%). In 2 of the 5 cases which remained negative at $18 \mathrm{~h}$, blue dye was injected and visualized an SN in both cases. 3 of 27 patients only had early images, all of which showed SNs. The overall detection rate after neoadjuvant chemotherapy was $23 / 27$ $(85 \%)$.

\section{Discussion}

Considering the consistency with which guidelines recommend SNB as the standard of care for many patients with early breast cancer, and considering that this is by far the most common cancer in women, the lack of clarity of the guidelines on technical details is surprising. Even very recent updates of widely used German [2], ASCO [4] and NCCN [3] guidelines provide little if any guidance on technique, tracers or timing. In our study, we used $4 \times 37 \mathrm{MBq}{ }^{99 \mathrm{~m}} \mathrm{Tc}$ nanocolloid, which we applied in a subcutaneous fashion around the areola. ${ }^{99 \mathrm{~m}} \mathrm{Tc}$ is a rather small colloid which is quickly transported to the nodes but remains in the nodes long enough to permit a delayed image after $18 \mathrm{~h}[1,16]$. The dosage of $148 \mathrm{MBq}$ is consis- 


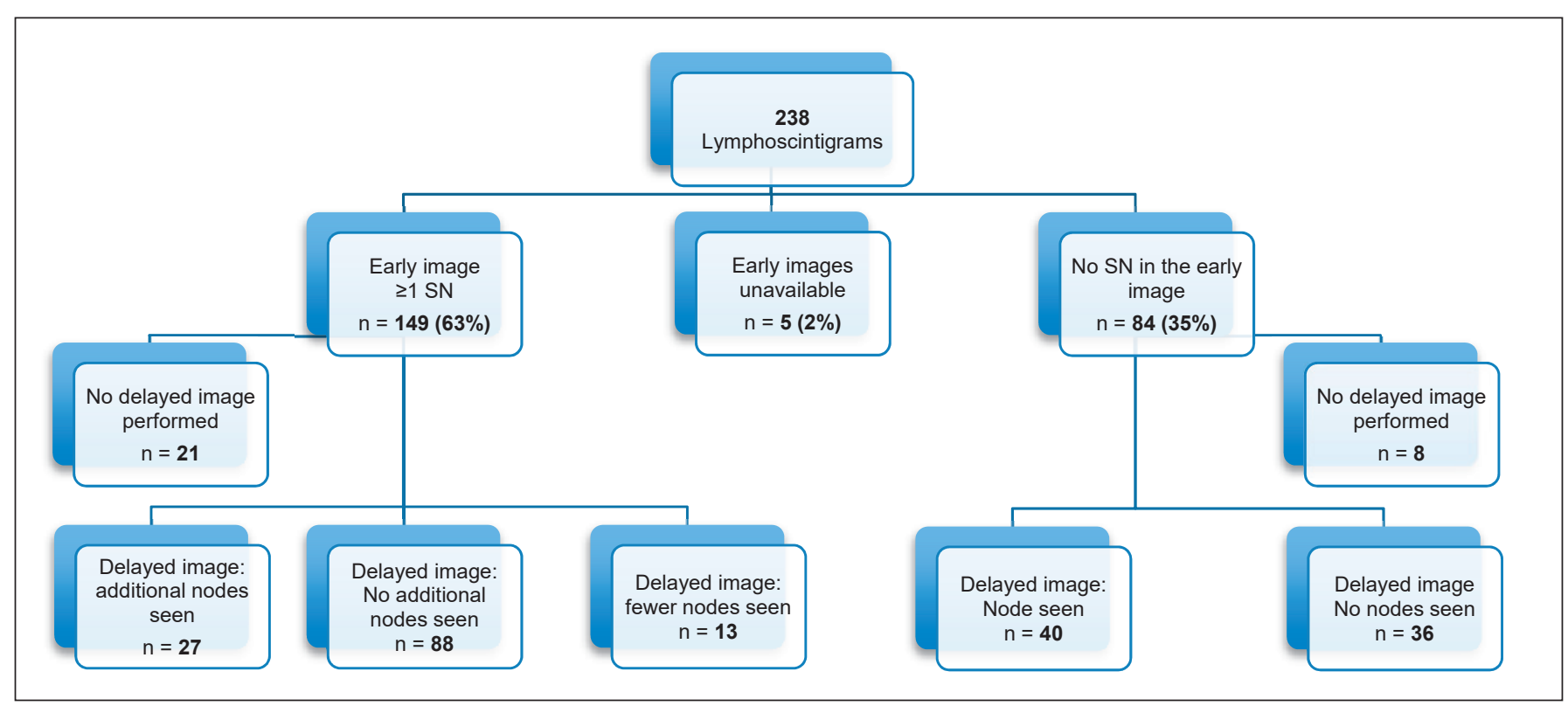

Fig. 1. Flowchart of 238 scintigrams in 232 patients.

Fig. 2. Early and delayed lymphoscintigraphy pictures showing no SLN in the early images and one obvious SLN in the delayed images.

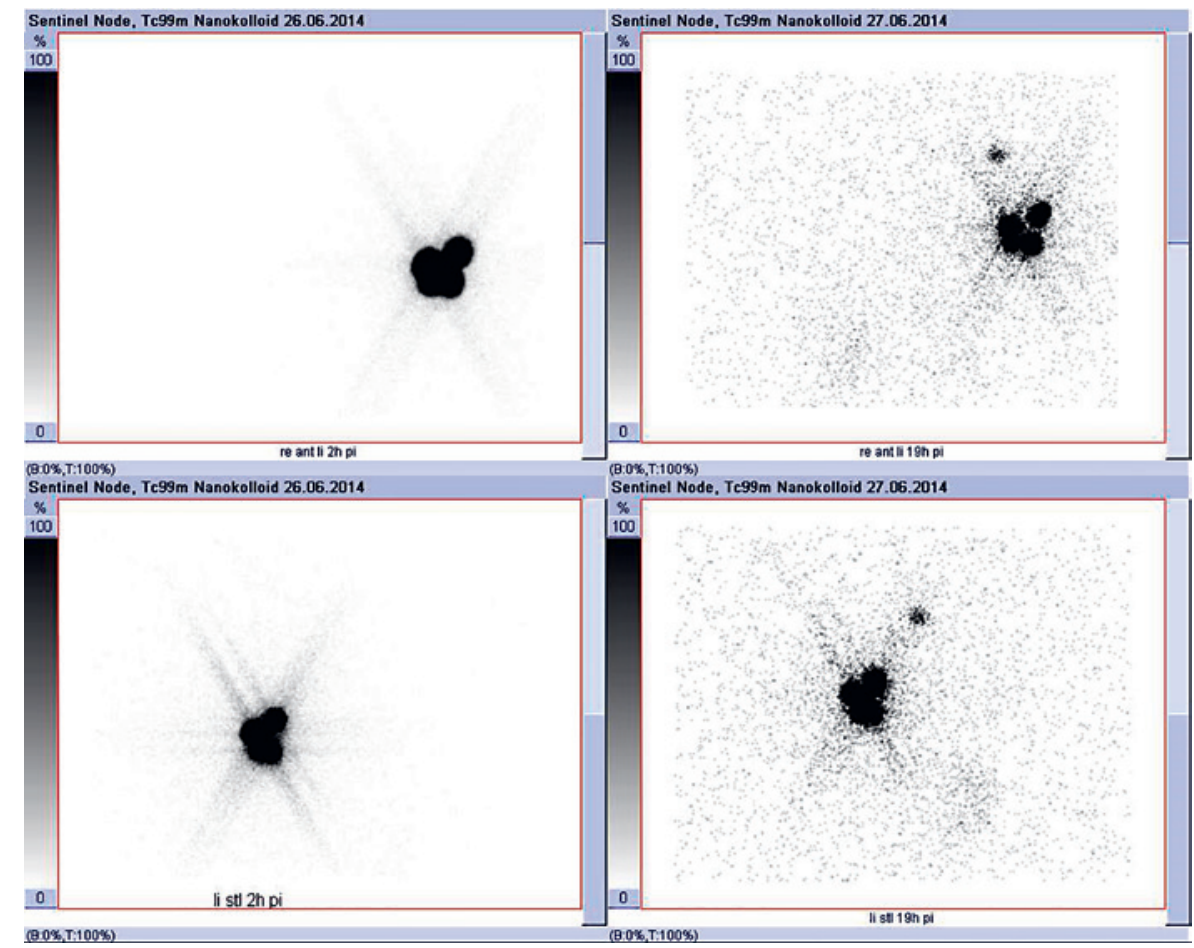

tent with guidelines [16]. Because of the sufficiently high amount of activity, we were able to ensure an enrichment of the tracer in the delayed planar images performed $18 \mathrm{~h}$ p.i. and also in the SPECT-CT.

Guidelines are vague on the timing of lymphoscintigraphy $[1-3,5,6,16]$. Either the possibility of performing an early and a delayed image is left open $[1,6]$ or there is nothing at all on the specific time of the lymphoscintig- raphy $[2,5]$. Neither the NCCN breast cancer guidelines [5] nor the German breast cancer guidelines [2] provide detail on the question of when lymphoscintigraphy images should be performed and when a delayed image is necessary. The 2014 interdisciplinary guidelines of the German Society of Nuclear Medicine are the most specific on the timing of lymphoscintigraphy in breast cancer [6]. These guidelines stipulate an early image with the 
possibility of a delayed image up to $24 \mathrm{~h}$ p.i. Furthermore, in case of nonvisualization after $1 \mathrm{~h}$ p.i., they suggest a 5 -min massage of the injection site or warming the breast. If this is not successful, the German nuclear medicine guidelines recommend a subdermal or subareolar reinjection [6]. Interestingly, the recent German AGO Guidelines [17] are now ambivalent ("+/-") for the need for preoperative lymphoscintigraphy at all.

The results of our study suggest that delayed images $18 \mathrm{~h}$ p.i. are able to show an SLN in 52\% of cases where the early images were negative. This represents actionable additional clinical information. This may be due to the dose of the tracer, which was high enough [17], and also to the subcutaneous application of the tracer [18]. With subcutaneous application, the tracer has a more moderate transit time than with intradermal application.

Our early scintigraphic detection rate of $63 \%$ is modest. Other studies report early detection rates of $41-65 \%$ [19], 68\% [20], 73\% [15], 91\% [21], 93\% [22], and 98\% [23]. At our unit, only clearly visible lymph nodes are defined as SLN in the early pictures. Enrichments which are low in contrast are normally read as negative, in the knowledge that there will be a later reading. Also, we do not massage or apply heat to the breast after injecting the tracer. Our overall detection rate including the delayed images was $81 \%$, which is similar to the rates reported by others: 96\% [15], 98\% [21], 96\% [23], 88\% [22], 72\% [20], and $82 \%$ [19].

Recent studies comparing 1-day and 2-day protocols continue to be ambivalent. Mount et al. [24] found a 2-day protocol to be "reliable" compared with a 1-day protocol. In contrast, Unkart et al. [25] found similar outcomes between 1-day and 2-day protocols. It is likely that local logistical issues and infrastructure influence practice.
In summary, the results of our series indicate that delayed scintigraphy is potentially useful if early scintigraphy fails to show an SLN [22]. In these patients, we were able to extend the clinical result and gain actionable information. This is consistent with the results of others $[19,24,25]$ who also found no significant impact of delayed imaging in patients in whom an $\mathrm{SN}$ can be visualized at immediate imaging.

\section{Statement of Ethics}

The study protocol was approved by the Ethics Committee of the Medical University of Graz. Written informed consent was waived as this was a retrospective review.

\section{Disclosure Statement}

The authors have no conflicts of interest to declare.

\section{Funding Sources}

This project received no external funding.

\section{Author Contributions}

Dr. Taumberger wrote the protocol, collected data and wrote the first draft of the manuscript. Dr. Pernthaler cowrote the protocol, collected data, reviewed scans and oversaw all versions of the manuscript. Thomas Schwarz collected data and reviewed scans. Drs. Bjelic-Radisic, Pristauz, Aigner and Tamussino supervised the protocol and data analysis and helped write the paper. All authors reviewed and approved the final version of the manuscript.

\section{References}

1 Buscombe J, Paganelli G, Burak ZE, Waddington W, Maublant J, Prats E, et al.; European Association of Nuclear Medicine Oncology Committee and Dosimetry Committee. Sentinel node in breast cancer procedural guidelines. Eur J Nucl Med Mol Imaging. 2007 Dec;34(12):2154-9.

2 Leitlinienprogramm Onkologie. S3-Leitlinie Früherkennung, Diagnose, Therapie und Nachsorge des Mammakarzinoms, Version 4.1, 2018 AWMF Registernummer: 032045OL [accessed 2018 Nov 9]. Available from: www.leitlinienprogramm-onkologie.de/ leitlinien/mammakarzinom.
3 Kuehn T, Bembenek A, Decker T, Munz DL, Sautter-Bihl ML, Untch M, et al.; Consensus Committee of the German Society of Senology. A concept for the clinical implementation of sentinel lymph node biopsy in patients with breast carcinoma with special regard to quality assurance. Cancer. 2005 Feb; 103(3): 451-61.

4 Lyman GH, Somerfield MR, Bosserman LD, Perkins CL, Weaver DL, Giuliano AE. Sentinel lymph node biopsy for patients with earlystage breast cancer: American Society of Clinical Oncology Clinical Practice Guideline Update. J Clin Oncol. 2017 Feb;35(5):561-4.

5 NCCN Clinical Practice Guidelines in Oncology. Breast Cancer - Verson 3.2018 (October 25, 2018) [accessed 2018 Nov 9]. Available from: www.nccn.org/professionals/physician_gls/pdf/breast.pdf.
6 Schmidt M, Bares R, Brenner W, Buck A, Grünwald F, Kopp J, et al. DGN-Handlungsempfehlung (S1-Leitlinie) Verfahrensanweisung für die technische Durchführung der nuklearmedizinischen Wächter-Lymphknoten-Diagnostik. Stand 10/2014 - AWMFRegisternummer 031-033 [accessed 2018 Nov 9]. Available from: www.awmf.org/uploads/ t $x_{-}$s z leitlinien/0 31 - 033 l_ S1_W\%C3\%A4chter_Lymphknoten_Diagnostik_2014-10.pdf.

7 Zurrida S, Veronesi U. Milestones in breast cancer treatment. Breast J. 2015 Jan-Feb; 21(1):3-12.

8 Kauffmann GW, Moser E, Sauer R. Radiologie. 3rd ed. München: Elsevier, Urban \& Fischer Verlag; 2006. 772 pp. 
9 Caruso G, Cipolla C, Costa R, Morabito A, Latteri S, Fricano S, et al. Lymphoscintigraphy with peritumoral injection versus lymphoscintigraphy with subdermal periareolar injection of technetium-labeled human albumin to identify sentinel lymph nodes in breast cancer patients. Acta Radiol. 2014 Feb;55(1):39-44.

10 Klimberg VS, Rubio IT, Henry R, Cowan C, Colvert M, Korourian S. Subareolar versus peritumoral injection for location of the sentinel lymph node. Ann Surg. 1999 Jun;229(6): 860-4.

11 McMasters KM, Wong SL, Martin RC 2nd, Chao C, Tuttle TM, Noyes RD, et al.; University of Louisville Breast Cancer Study Group. Dermal injection of radioactive colloid is superior to peritumoral injection for breast cancer sentinel lymph node biopsy: results of a multiinstitutional study. Ann Surg. 2001 May; 233(5):676-87.

12 Motomura K, Komoike Y, Hasegawa Y, Kasugai $\mathrm{T}$, Inaji $\mathrm{H}$, Noguchi $\mathrm{S}$, et al. Intradermal radioisotope injection is superior to subdermal injection for the identification of the sentinel node in breast cancer patients. J Surg Oncol. 2003 Feb;82(2):91-6.

13 Mudun A, Sanli Y, Ozmen V, Turkmen C, Ozel S, Eroglu A, et al. Comparison of different injection sites of radionuclide for sentinel lymph node detection in breast cancer: single institution experience. Clin Nucl Med. 2008 Apr;33(4):262-7.
14 Pelosi E, Bellò M, Giors M, Ala A, Giani R, Bussone R, et al. Sentinel lymph node detection in patients with early-stage breast cancer: comparison of periareolar and subdermal/ peritumoral injection techniques. J Nucl Med. 2004 Feb;45(2):220-5

15 Sadeghi R, Forghani MN, Memar B, Rajabi Mashhadi MT, Dabbagh Kakhki VR, Abdollahi A, et al. How long the lymphoscintigraphy imaging should be continued for sentinel lymph node mapping? Ann Nucl Med. 2009 Aug;23(6):507-10.

16 Giammarile F, Alazraki N, Aarsvold JN, Audisio RA, Glass E, Grant SF, et al. The EANM and SNMMI practice guideline for lymphoscintigraphy and sentinel node localization in breast cancer. Eur J Nucl Med Mol Imaging. 2013 Dec;40(12):1932-47.

17 Kommission Mamma der Arbeitsgemeinschaft Gynäkologische Onkologie in der Deutschen Gesellschaft für Gynäkologie und Geburtshilfe. 2018 [accessed 2018 Nov 9]. Available from: www.ago-online.de filead$\mathrm{min} /$ downloads/leitlinien/mamma/2018-03.

18 Tanis PJ, Nieweg OE, Valdés Olmos RA, Kroon BB. Anatomy and physiology of lymphatic drainage of the breast from the perspective of sentinel node biopsy. J Am Coll Surg. 2001 Mar;192(3):399-409.

19 Wang H, Heck K, Pruitt SK, Wong TZ, Scheri RP, Georgiade GS, et al. Impact of delayed lymphoscintigraphy for sentinel lymphnode biopsy for breast cancer. J Surg Oncol. 2015 Jun;111(8):931-4.
20 Yeung HW, Cody HS 3rd, Turlakow A, Riedel ER, Fey J, Gonen M, et al. Lymphoscintigraphy and sentinel node localization in breast cancer patients: a comparison between 1-day and 2-day protocols. J Nucl Med. 2001 Mar; 42(3):420-3.

21 Gutman F, Sanson A, Piquenot JM, Hitzel A, Ladonne JM, Dessogne P, et al. Intra-individual comparison of sentinel lymph node scintigraphy on the day of injection and on the following day in breast cancer. Nucl Med Commun. 2006 Jan;27(1):5-9.

22 Wang HY, Tsai CC, Hung GU, Lin WY. Effectiveness of delayed 2-day lymphoscintigraphy on sentinel lymph node detection in patients with breast cancer with negative early lymphoscintigraphy. Clin Nucl Med. 2006 Sep;31(9):523-6.

23 Jangjoo A, Forghani MN, Mehrabibahar M, Rezapanah A, Kakhki VR, Zakavi SR, et al. Comparison of early and delayed lymphoscintigraphy images of early breast cancer patients undergoing sentinel node mapping. Nucl Med Commun. 2010 Jun;31(6):521-5.

24 Mount MG, White NR, Nguyen CL, Orr RK, Hird RB. Evaluating one day versus two days preoperative lymphoscintigraphy protocols for sentinel lymph node biopsy in breast cancer. Am Surg. 2015 May;81(5):454-7.

25 Unkart JT, Proudfoot J, Wallace AM. Outcomes of "one-day" vs "two-day" injection protocols using Tc-99m tilmanocept for sentinel lymph node biopsy in breast cancer. Breast J. 2018 Jul;24(4):526-30. 